\title{
El sistema de fuentes de la función pública colombiana: una relectura desde el valor del derecho del trabajo*
}

\author{
Hernán Darío Vergara Mesa**
}

Recibido: 20 de octubre de 2016 • Aprobado: 5 de junio de 2017

DOI: 10.22395/ojum.v16n32al

\begin{abstract}
RESUMEN
El escrito aborda críticamente el unidimensionalismo que ha caracterizado la regulación de la relación de trabajo que sostienen los empleados públicos con el Estado, reivindica el valor de la fuente laboral para dicho efecto y, a partir de eso, propone la relectura del sistema de fuentes en el ámbito de la función pública, intentando mostrar que la dimensión jurídica de la referida fuente no puede ser desconocida por los operadores jurídicos correspondientes.
\end{abstract}

Palabras clave: función pública; sistema de fuentes del derecho; normas internacionales del trabajo; principio pro homine.

Este artículo es el resultado del proyecto de investigación titulado "Función pública y derecho del trabajo en Colombia, período 2006-2011", aprobado por el Comité para el Desarrollo de la Investigación de la Universidad de Antioquia (CODI), según Acta n. 655 del 30 de abril de 2013. El artículo se enmarca dentro de la línea de Derecho público, perteneciente al Grupo de Investigación Derecho y Propiedad.

** Abogado y magíster en Derecho de la Universidad de Antioquia. Especialista en Derecho Administrativo de la Universidad de Medellín. Candidato a doctor en Derecho de la Universidad de Buenos Aires, Argentina. Profesor titular de la Facultad de Derecho y Ciencias Políticas de la Universidad de Antioquia. Correo electrónico: hernan.vergara@udea.edu.co 


\section{The system of sources of the Colombian civil service: A review from labor law value}

\section{ABSTRACT}

This paper critically addresses the one-dimensional that has featured the regulation of the employment relationship that public employees hold with the State. It also claims the value of the labor source for such effect, and from this point, it suggests a critical view of the system of sources in the scope of the civil service. Besides, it intends to show that the legal dimension of the said source cannot be unknown by the corresponding legal operators.

Keywords: civil service; system of law sources; international labor standards; pro homine principle.

\section{0 sistema de fontes da função pública colombiana: uma releitura a partir do valor do direito do trabalho}

\section{RESUMO}

Neste texto, aborda-se criticamente o unidimensionalismo que caracteriza a regulamentação da relação de trabalho entre o Estado e os funcionários públicos; reivindica-se o valor da fonte trabalhista para esse efeito e, a partir disso, propõese a releitura do sistema de fontes no âmbito da função pública na tentativa de mostrar que a dimensão jurídica da referida fonte não pode ser desconhecida pelos operadores jurídicos correspondentes.

Palavras-chave: função pública; normas internacionais do trabalho; princípio pro homine; sistema de fontes do direito. 


\section{INTRODUCCIÓN}

Los empleados públicos se asocian usualmente con la representación del Estado, con el cumplimiento de las funciones públicas y con la satisfacción del interés general. Pocas veces son reconocidos como trabajadores, es decir, como personas que prestan su fuerza de trabajo a favor del Estado, normalmente en condiciones de subordinación y a cambio de una remuneración. Ha resultado aún más extraña la posibilidad de que se les apliquen las normas de protección que rigen las relaciones laborales de otros grupos de trabajadores, pues en su caso resulta lógico que se sometan a un estatuto especial que se adecue a las características del servicio que se les asigna y que opera en el plano del derecho público.

Ese imaginario, formado a partir de múltiples causas a lo largo de los siglos, no ha sido superado completamente en Colombia, a pesar de que las disposiciones constitucionales ofrecen un panorama diferente, en el que el principio de protección especial al trabajo se muestra como un mandato llamado a regir la relación laboral al margen del ámbito público o privado en que se configure (Const., 1991, art. 25). El derecho público, entonces, con su particular sistema de fuentes y principios, es el configurador por excelencia de las condiciones de trabajo de los empleados y, al mismo tiempo, de sus derechos y deberes, dejando poco espacio al estatuto laboral general y a las instituciones que lo determinan.

Es de considerar, sin embargo, que la norma laboral no puede ser eludida como fuente de derecho para regular la relación de trabajo pública, específicamente la que sostienen los empleados públicos con el Estado. Los elementos que provienen de la Constitución y, sobre todo, del derecho internacional, ofrecen la posibilidad de mostrar un panorama diferente, a partir de los cuales el protagonismo de dicha fuente se visualiza en toda su plenitud.

\section{METODOLOGÍA}

La investigación que da lugar a este análisis, tuvo un diseño cualitativo y de tipo analítico-descriptivo, y fue planteada a partir del problema de la prevalencia de las fuentes del derecho administrativo sobre las del derecho laboral en las causas presentadas por los empleados públicos en materia de estabilidad laboral. Para el efecto, se proyectó la siguiente hipótesis: en materia de regímenes salarial y de estabilidad laboral, los operadores jurídicos, especialmente los jueces administrativos, no hacen uso de las instituciones del derecho del trabajo y, por ende, aplican sólo las fuentes de derecho administrativo.

Para comprobar dicha hipótesis, se realizó una pesquisa a sentencias de la Sección Segunda del Consejo de Estado colombiano, producidas durante el período comprendido entre los años 2006 a 2011, en las cuales se indagó por el grado de utilización y aplicación de las fuentes del derecho del trabajo en la resolución de las causas laborales propuestas por los empleados públicos contra el Estado, en materias relacionadas con los regímenes de estabilidad, salarial y prestacional. 
Para el estudio de esta clase de sentencias se diseñaron fichas de recolección de la información, organizadas de acuerdo con las categorías de análisis establecidas en la investigación, estos es, la invocación, la mención y la aplicación efectiva de las instituciones del derecho laboral por parte de este juez al fallar las causas puestas a su consideración. Se elaboraron, igualmente, cuadros comparativos para facilitar el análisis de la información recolectada.

\section{RESULTADOS}

\section{El concepto y las características de la relación laboral estatal}

Existe consenso alrededor de la idea de que la relación de trabajo es una modalidad de relación jurídica que se configura entre un trabajador y un empleador, a partir de la confluencia de tres elementos básicos: la prestación de servicios personales, la continuada subordinación al empleador y el pago de un salario por la retribución de los servicios (OIT, 2006); en Colombia el asunto no se asume de modo diferente (Decreto-Ley 2663, 1950, art. 23). Ese tipo de relaciones se configuran tanto en el ámbito privado como en el público, en este último caso aun en el evento en que la prestación de los servicios se haga dentro de la esfera de los cometidos esenciales del Estado (Sentencia C-614, 2009), lo cual indica que el Estado puede comportarse como empleador independientemente de los roles que esté llamado a cumplir en los diversos sectores que comprende la actividad pública.
Cabe hacer en este punto algunas aclaraciones que permitan comprender la vocación omnicomprensiva de la relación laboral en el ámbito público. Estas aclaraciones se refieren tanto a la índole de las funciones que cumple en cada caso el Estado, como a la calidad de los servidores encargados de ejecutarlas, en términos del vínculo que sostienen con aquel.

Como una reedición de la clásica distinción en el derecho público entre los llamados actos de autoridad y los actos de gestión, que se sustenta fundamentalmente en la posibilidad que tienen las autoridades de obrar prevalidas de las prerrogativas del poder público (García de Enterría, 1963, pág. 101), desde hace varias décadas se viene sugiriendo que las funciones estatales se despliegan de diversas maneras y con diferentes propósitos (Bresser Pereira, 1998, pág. 527 y ss.), funciones que, por razones metodológicas, pueden ser reconducibles a dos grandes bloques: el bloque del Estado "soberano" y el bloque del Estado "empresario". Por la gradualidad que caracteriza todo el proceso de asignación de tales competencias entre órganos colectivos e individuales (Merkl, 2004, pág. 388), las consecuencias jurídicas de dicha clasificación son significativas en términos organizativos y laborales.

En efecto, desde el punto de vista organizativo, en el llamado bloque "soberano" se incorporan todos aquellos órganos o entidades que tienen a su cargo el cumplimiento de funciones esencialmente públicas, es decir, aquellas cuya titularidad reposa en el Estado de conformidad 
con la Constitución Política y la ley, y que se caracterizan primordialmente por su satisfacción con criterios de gratuidad, igualdad y universalidad, y no con la lógica de participación en un mercado o la búsqueda de rentabilidad económica. Es el caso de la legislación, la Administración de Justicia, el control, la regulación, la definición, aprobación y coordinación de las políticas públicas, entre otras, en las que las autoridades pueden expresarse a partir de decisiones que tienen repercusiones sociales más o menos amplias.

En el bloque "empresario", por su parte, se incorporan todos aquellos entes $\mathrm{u}$ organizaciones cuyas actividades se desenvuelven en el ámbito de la competencia con los agentes privados y con la finalidad de lograr un lucro, en este caso con requerimientos del servicio que no difieren del exigido a los particulares, orientándose, por tanto, por criterios de eficiencia y calidad. En este caso, la faceta de autoridad o el ejercicio de poder público son excepcionales y dependientes de la expresa autorización legal.

Sin excluir la posibilidad de que muchos ámbitos de actuación del Estado generen en la actualidad un gran debate a la hora de su clasificación en alguno de los mencionados bloques ${ }^{1}$, lo cierto es que estos proporcionan una base teórica útil para explicar los medios organizativos que utiliza el Estado colombiano para cumplir

1 Piénsese, por ejemplo, en los servicios de administración de recursos de la seguridad social o en la prestación de servicios de salud que está a cargo de las empresas sociales del Estado, o en las actividades de fomento a muchos sectores como el de seguridad, la recreación y el deporte, la vivienda, el desarrollo urbano, entre otros. sus propósitos y los regímenes jurídicos laborales que asigna a cada uno de ellos.

Para solo hacer referencia a la Administración Pública y, fundamentalmente a la Rama Ejecutiva, que es la que aglomera la inmensa mayoría de entes públicos, la Ley 489, 1998 (art. 39) dispone su integración a partir de tres grupos de organismos: unos denominados principales, otros adscritos y otros vinculados. A los principales corresponde la orientación, coordinación y control de las actividades de los organismos que están adscritos y/o vinculados a sus respectivos sectores, en tanto que el carácter de adscrito o vinculado es dependiente de la naturaleza jurídica de las funciones que se asignan, esto es, si son administrativas o de gestión económica, respectivamente.

La plataforma teórica de esta clasificación legal no es otra que la sustentada en los llamados bloques de Estado "soberano", en donde se ubican los organismos principales y los adscritos, y de Estado "empresario", en el que se sitúan los organismos vinculados; por eso resulta lógico que los primeros se rijan por el derecho público, en tanto que los segundos lo hagan por el derecho privado, y esto vale para el régimen laboral que se aplica a cada uno de ellos, al punto que las formas de vinculación de las personas que les prestan sus servicios cambia notablemente, pues en este ámbito el derecho público prohíja formas de vinculación laboral especial, como la legal y reglamentaria -estatutaria-, mientras que el derecho privado adopta las formas contractuales, que es el caso del contrato de trabajo. 
Bajo este esquema, en los organismos creados como principales y adscritos, la regla general son los empleados públicos; en los organismos vinculados lo son los trabajadores, algunos de los cuales pueden ser calificados como trabajadores oficiales (Decreto Extraordinario 3135, 1968, art. 5), pudiendo en ambos casos configurarse excepciones, las cuales se construyen básicamente a partir de criterios materiales ${ }^{2}$. Esto permite evidenciar que en el interior del Estado existe una clase de relación de trabajo que es regulada preferentemente por el derecho público, es decir, bajo la lógica del sistema de fuentes del derecho público administrativo, y no, como pareciera ser lo normal, por el derecho laboral.

\section{El problema de las fuentes de derecho en la regulación de la relación laboral estatal}

El concepto de fuente es uno de los más difusos en la teoría del derecho, pues puede tener distintas acepciones, bien en sentido material o bien formal. De acuerdo con Guastini (1999, pág. 81 y ss.), una noción material de fuente de derecho es aquella que se identifica con ciertos actos o hechos cuyo contenido sea la producción de normas, los cuales solo pueden ser identificados a posteriori y no con base en procedimientos de enumeración jurídica; entre tanto, una noción formal, hace

2 En los organismos principales y adscritos, la excepción se configura a partir del concepto de construcción y sostenimiento de obra pública; en tanto que, en algunos organismos vinculados, se configura a partir del concepto de dirección y confianza (Decreto Extraordinario 3135, 1968, art. 5). alusión a todo acto o hecho autorizado a producir normas, independientemente de su contenido, lo cual puede constatarse a priori a partir de la identificación de las normas positivas que autorizan a tales actos y hechos a crear derecho. Esta acepción formal, según De Otto (1988, pp. 70 y 75), es la ordinariamente usada en el ámbito jurídico, pues en él la expresión se refiere a aquello a lo que el "ordenamiento confiere la virtualidad de crear una norma", lo cual exige concentrar toda la atención en el sistema constitucional de organización del Estado y en los procedimientos y funciones de sus órganos.

Ross (2007, pp. 356-357) sitúa el problema de las fuentes del derecho en la falta de referencia a un plano metodológicamente unívoco, teniendo en cuenta que existen al menos tres planteamientos con consecuencias diversas, a saber, el sociológico (acerca de las causas de que un sistema jurídico llegue a existir), el ético (sobre la fuerza moralmente vinculante que supuestamente cabe atribuir al ordenamiento jurídico) y el teórico-jurídico (en relación con el fundamento para saber que algo es derecho); por ello sostiene que para evitar una confusión metodológica es preciso decidirse por uno de esos tres planteamientos, aunque recomienda para ello utilizar el plano teórico-jurídico, porque es el único que entra en el ámbito del sistema de conocimiento específicamente jurídico.

Es así como, según el citado autor, habría que considerar que la definición real del concepto de fuente del derecho depende, a la larga, de la teoría sobre la naturaleza 
del derecho de la que se parta, de donde se obtiene que la teoría sociológica de las fuentes del derecho siempre ha tendido a estimar a la costumbre como la fuente fundamental de todo el derecho, y a todo derecho, en última instancia, como consuetudinario; mientras que en una teoría, como la normativista de Kelsen, el Estado es la fuente de todo el derecho, a partir de la derivación de unas normas que se desprenden de otras, hasta que se parte de una primera norma fundamental, cuya validez se presupone como fuente independiente y originaria (Ross, 2007, pp. 369-370).

No se intenta en este caso intervenir en la discusión sobre qué deba entenderse por fuentes del derecho, sobre las distintas posturas, análisis y variables que asumen y que tienen gran pertinencia académica en los estudios introductorios y filosóficos del derecho. Se asume, sí, la idea de que las fuentes del derecho hacen relación a todos aquellos actos a los cuales el ordenamiento jurídico atribuye la virtualidad de producir normas jurídicas, sobre todo porque el sistema colombiano de fuentes del derecho, y en particular el del derecho público, ha evolucionado y se ha explicado a partir de una cultura formalista influenciada, entre otros elementos, por la doctrina normativista de Kelsen (Medina, 2004, pp. 129 y ss.). Ello supone entonces hacer una revisión del ordenamiento jurídico colombiano para preguntarse hasta dónde los actos emitidos por ciertas autoridades tienen la capacidad de producir normas de obligatorio cumplimiento, al menos en el ámbito de la función pública.
Ahora bien, si se tiene en cuenta que la Constitución Política ordena la protección especial al trabajo en todas sus modalidades, incluidas las de derecho público, y la extensión a ellas de los principios mínimos de trabajo (Sentencia T-457, 1992), debería ser muy claro que las disposiciones de contenido laboral, que se pueden producir en múltiples instancias y que se instalan en los distintos niveles del sistema de fuentes colombiano, son pertinentes y aplicables a las relaciones de trabajo que se configuran con el Estado. La descripción efectuada en el acápite anterior, entonces, no dejaría de ser más que un simple esfuerzo por establecer la relación técnico-administrativa entre los fines y los medios que el Estado utiliza para el cumplimiento de sus funciones, sin que eso afecte la obligatoriedad de la norma laboral. Sin embargo, lo cierto es que la clasificación entre los servidores públicos resultante de aquella relación sí ha tenido implicaciones con respecto a las fuentes del derecho tomadas en cuenta para la regulación del fenómeno laboral estatal que, en el caso de los empleados, han sido las del derecho público.

La raíz de tales implicaciones parece hallarse en el diseño institucional que desde hace más de cinco décadas dispuso el legislador colombiano para asignar el conocimiento de las causas laborales contra el Estado, basado en un esquema de dualidad jurisdiccional, según la cual el juzgamiento de las controversias relativas al contrato de trabajo es de la jurisdicción ordinaria laboral, en tanto que el juzgamiento de las provenientes de relaciones legales y reglamentarias es de 
la jurisdicción contencioso-administrativa (Vergara, 2012).

Se ha podido diagnosticar, para períodos concretos y en regímenes como los de estabilidad, salario y prestaciones sociales, la sistemática inaplicación que han sufrido las instituciones de derecho laboral en el escenario contencioso-administrativo (Vergara, 2015). Allí la fuente de derecho público se constituye en el referente principal e inmediato para la solución de las controversias que plantean los empleados públicos contra el Estado, y lo hace bajo la lógica de los principios e instituciones que son propias de esta rama del derecho. Aparte de que en dicho escenario no existe un procedimiento especial para instruir esta clase asuntos y que se les somete, por tanto, al trámite general de las acciones de nulidad, todo su desarrollo termina siendo condicionado significativamente por la figura del acto administrativo, por el despliegue consecuente de la llamada auto-tutela administrativa, y por el protagonismo especial de la presunción de legalidad (Ley 1437, 2011, art. 88).

Como se sabe, la presunción de legalidad tiene el efecto de salvaguardar la existencia y validez del acto administrativo, así como su exigibilidad y ejecutoriedad, hasta tanto no sea demandado y se produzca su anulación por el juez contencioso-administrativo (Gordillo, 2011, pág. 20 a 24). Con esta presunción, que procura garantizar los intereses generales que se encuentran en cabeza de la Administración Pública, se neutraliza en gran medida el principio de protección especial al trabajo, pues las reglas de la favorabilidad laboral y la condición más beneficiosa para el empleado se tornan inoperantes ante la obligación que tiene este de asumir en dicho escenario las cargas probatorias que regularmente estarían en cabeza del empleador.

Lo anterior muestra que existe una relación de trabajo que es sometida en Colombia, tanto sustantiva como procesalmente, a los derroteros trazados por el derecho público y a la que solo alcanza tangencialmente el derecho laboral (Vergara, 2015, pp. 184 a 189). Esto representa un verdadero problema para la vocación universal que tienen las normas laborales de regular cualquier manifestación del trabajo humano, al margen, entre otros, de quien cumpla en un momento determinado el rol de empleador (Balbín, 2005, p. 49), sobre todo tratándose de una relación que supone, como en el caso de los empleados públicos, un alto grado de subordinación respecto a un empleador poderoso, como es el Estado (Fernández, 1986, p. 887).

\section{El valor jurídico de la fuente de derecho laboral}

El hecho de que la fuente de derecho laboral no sea ordinariamente tenida en cuenta por los operadores jurídicos colombianos, al menos en algunos ámbitos de la relación de trabajo estatal, puede verse como la consecuencia obvia del modelo de función pública adoptado por el país desde hace más de un siglo, y en el que es notable la influencia del derecho administrativo francés (Vergara, 2015). En este modelo, las notas relativas al control de legalidad, a la unilateralidad, al juez 
especial y a la protección del interés general marcan decididamente los rasgos de la gestión de los asuntos laborales del Estado, pues, al ponerlos en el plano estrictamente administrativo, crea para ellos la necesidad de una normativa especial, "derogatoria" del derecho común, para su regulación (Rivero, 2002, p. 42).

No obstante, si bien desde el punto de vista histórico es posible justificar tal omisión, sobre todo porque el derecho laboral solo empieza a tener trascendencia a partir de los años 20 del siglo pasado con la creación de la Organización Internacional del Trabajo (OIT) (Válticos, 1977, pp. 199 y ss.), y en Colombia, en particular, por la falta de normas sustantivas relativas al tema, que solo obtuvieron una codificación en los años 50 (Decreto-Ley 2663, 1950), lo cierto es que son muchas las décadas que han pasado desde entonces, durante las cuales el derecho del trabajo ha venido, paulatina pero consistentemente, ampliando su vocación regulativa y mejorando su estatus jurídico, en el marco tanto del derecho nacional como en el internacional.

No es ninguna novedad señalar que en el orden interno colombiano, aparte de que en ningún momento se ha puesto en duda el carácter laboral de la relación que sostienen los empleados públicos con el Estado ${ }^{3}$, las disposiciones constituciona-

3 En realidad, las normas legales anteriores a la Constitución Política de 1991 aceptan el carácter laboral de la referida relación, tal como lo hace expresamente el Decreto Ley 2663, 1950, arts. 3 y 4; implícitamente ya lo había hecho la Ley 6, 1945, y posteriomente el Decreto Extraordinario 3135, 1968, el Decreto Reglamentario 1848, 1969 y el Decreto Extraordinario 1045, 1978, entre otros. les actuales son por sí mismas reveladoras del significado que ha llegado a adquirir el trabajo humano como bien jurídico objeto de una especial protección (Const., 1991, Preámbulo y arts. 1 y 25). A partir de su interpretación la jurisprudencia constitucional ha afirmado que los derechos que se desprenden del trabajo "gozan de la doble condición de derecho humano y derecho fundamental", esto es, son requisitos indispensables del Estado que no pueden estar ausentes de su legalidad (Sentencia C-969, 2012).

Pero lo que quizá resulta más representativo a la hora de dimensionar el significado jurídico de la fuente de derecho laboral es el amplio reconocimiento que ha logrado a nivel del derecho internacional público. Sin necesidad de referirse a los motivos económicos y humanitarios que propiciaron la construcción de una normativa internacional que orientara la regulación del trabajo humano en condiciones de dignidad para la mayoría de los países del mundo (De la Cueva, 1990, pág. 26), el reconocimiento de este fenómeno en los más importantes instrumentos internacionales sobre derechos humanos es suficientemente indicativo de la importancia que ha adquirido y que, se considera, tiene su más relevante repercusión en el sistema de fuentes del derecho.

Son muchas las razones por las cuales al trabajo se le atribuye la condición de derecho humano. La estrecha relación que sostiene con los derechos de libertad fáctica-(Alexy, 2008, pp. 447 y ss.), con la tutela de los más débiles (Ferrajoli, 2010, p. 56), con la dignidad humana y la satis- 
facción de necesidades básicas (Canessa, 2006, p. 43), y también por su positividad expresa (Bobbio, 1981, p. 127), son algunos de los motivos más frecuentes para aceptar dicha calificación.

Con un sentido práctico, este estudio se apoya en la positividad sostenida por Bobbio. Para este autor la mejor manera de identificar cuáles son los derechos humanos es descubriendo si en un período concreto de la historia han obtenido un consenso, pues es lo único que puede probarse fácticamente; y eso es lo que representa la Declaración Universal de los Derechos del Hombre: la única prueba de la existencia de un sistema de valores que por primera vez en la historia logra una adhesión general (Bobbio, 1981, p. 133). Esto es lo que se observa justamente con el derecho del trabajo. Por lo menos desde la segunda mitad del siglo veinte, el trabajo ha ocupado un lugar privilegiado en las más representativas declaraciones, pactos, protocolos y convenios internacionales que integran el llamado sistema internacional de derechos humanos, entre los cuales cabe destacar la Declaración Universal de los Derechos Humanos de 1948, el Pacto Internacional de Derechos Económicos, Sociales y Culturales de 1966, la Declaración Americana de Derechos Humanos de 1948 y el Protocolo Adicional a la Convención Americana sobre Derechos Humanos en Materia de Derechos Económicos, Sociales y Culturales de 1988, o "Protocolo de San Salvador".

Tales instrumentos han sido debidamente suscritos por Colombia de conformidad con la normativa vigente sobre el derecho de los tratados (ONU, 1969), así como la mayoría de los que se producen, ordenan y controlan a través del sistema especializado de normas internacionales del trabajo, en el seno de la OIT. Esto significa que son normas vinculantes en el orden interno del país.

El calificativo de derecho humano, por supuesto, tiene o debe tener consecuencias: favorece un juicio de mayor relevancia de los derechos (Del Hierro, 2000, pág. 353) o, en términos normativos, de las disposiciones que consagran y regulan el derecho al trabajo sobre las que reconocen otro tipo de derechos y potestades, al punto que pone en el plano de la discusión bien sea su mayor rango jurídico o bien su mayor importancia material.

En el presente estudio interesa explorar el rango normativo que tal condición otorga al derecho del trabajo en el específico ámbito de la función pública ${ }^{4}$. En este plano, su categorización está permeada por varios elementos: primero, por su connotación constitucional; segundo, por su calidad de objeto de regulación por el derecho internacional público y, tercero, por su condición de derecho humano, sujeto, por ende, a criterios de interpretación y aplicación especiales.

\footnotetext{
El problema relativo al mayor valor material de un derecho sobre otro es un análisis más propio de las visiones conflictivistas de los derechos fundamentales que, ante la confluencia de normas de igual rango jurídico, apelan al examen de proporcionalidad, examen en el cual los pesos abstractos y concretos de los derechos son determinantes para establecer su prevalencia relativa. Sobre el conflictivismo y sus notas características, cfr. Lopera, 2006, pp. 134 y ss.
} 
El primero de estos puntos se puede considerar pacíficamente aceptado. La Constitución Política deja muy pocas dudas sobre el rango que ostentan las normas laborales en el sistema jurídico colombiano. El preámbulo y los artículos 1,25 y 53 son lo suficientemente indicativos de la importancia que tiene el trabajo como uno de los elementos esenciales del Estado social, cuya observancia es de tal magnitud, que ha llevado a la Corte Constitucional a decir que

\begin{abstract}
[...] ante la existencia de controversias o conflictos laborales la Constitución debe ser interpretada y aplicada de suerte que los valores y principios que protegen y garantizan los derechos de los trabajadores tengan plena realización en procura de la dignidad de las personas (Sentencia T-097, 2006).
\end{abstract}

La misma Corte ha catalogado el trabajo como uno de los pocos bienes jurídicos sobre los que concurre la triple condición constitucional de valor, principio y derecho fundamental (Sentencia C-593, 2014), lo cual impone la obligación a todos los órganos del Estado, en todos sus niveles

\section{[...] de desarrollar políticas que amplíen y protejan el empleo, la conservación y creación de nue- vos puestos de trabajo, combatir la desocupación, y la preserva- ción de las condiciones laborales más benéficas para los trabaja- dores (Sentencia SU-484, 2008).}

En cuanto al segundo punto, es de señalar que los instrumentos internacionales, antes referenciados, son en su gran mayoría, reconocidos como integrantes del sistema internacional de protección de los derechos humanos, consagran derechos básicos de los trabajadores y están en su mayoría consagrados en el artículo 53 de la Constitución colombiana. Este reconocimiento posee una gran ventaja: ofrece un doble fundamento jurídico para la protección de estos derechos y, como corolario de ello, amplía los centros autorizados de interpretación y aplicación de las disposiciones respectivas en función de la definición de su contenido y alcances (Beaudonnet, 2009, pp. 92 y ss.). Estos instrumentos, cabe recordar, hacen parte de la normativa interna colombiana por virtud de lo dispuesto en los artículos 53 y 93 de la Carta, o sea, que bien pueden instalarse como partes del bloque de legalidad o de constitucionalidad, según sea el caso (Molina, 2005).

Así, por ejemplo, el Protocolo Adicional a la Convención Americana sobre Derechos Humanos en Materia de Derechos Económicos, Sociales y Culturales de 1988, contempla en su artículo 7. ${ }^{\circ}$ las denominadas "condiciones justas, equitativas y satisfactorias de trabajo". Allí se enlista una serie de derechos que tienen que ver, entre otros, con el acceso al empleo, a la estabilidad laboral, al descanso, al ascenso y, en particular, a una remuneración que asegure condiciones de subsistencia digna y a un salario equitativo e igual por trabajo igual, sin ninguna distinción. Este instrumento tiene el carácter de tratado internacional, ratificado por Colombia mediante la Ley 319 de 1996, o sea que es norma vinculante para los operado- 
res jurídicos nacionales; pero, además de eso, su interpretación y aplicación es competencia no solo de los tribunales y jueces colombianos, sino también, y por sobre todo, de los organismos del Sistema Interamericano de Derechos Humanos, en este caso, de la Comisión de la Corte Interamericana de Derechos Humanos.

Adicionalmente, por virtud del control de convencionalidad que rige el Sistema Interamericano de Derechos Humanos (Sagües, 2012), los jueces están obligados a tener en cuenta no solo las normas nacionales y las que consagra el tratado internacional respectivo -el Protocolo en este caso-, sino también la interpretación que ha hecho de las mismas la Corte Interamericana de Derechos Humanos, que es su máximo y último intérprete ("Caso Almonacid Arellano y otros contra el Estado de Chile", 2006), (SU-712, 2013).

Finalmente, el hecho de que esta clase de instrumentos tengan la calidad de tratados internacionales y, asimismo, regulatorios de derechos humanos desencadena para su interpretación y aplicación una serie de principios, criterios o reglas hermenéuticas de implicaciones excepcionales. Por un lado, tal calidad los ampara bajo el principio del "pacta sunt servanda", de modo tal que una vez entran en vigor obligan al Estado respectivo: i) a cumplirlos de buena fe (Convención de Viena, 1969, n. ${ }^{\circ}$ 26), ii) a no invocar las disposiciones de su derecho interno como justificación para incumplirlos (Convención de Viena, 1969, n. $\left.{ }^{\circ} 27\right) \mathrm{y}$, iii) a interpretarlos de buena fe, conforme al sentido corriente que haya de atribuirse a sus términos en el contexto en el que fueron adoptados y teniendo en cuenta su objeto y fin (Convención de Viena, 1969, n. ${ }^{\circ}$ 31 1).

La doctrina internacionalista ha considerado que obligaciones como las citadas, que en caso de incumplimiento acarrean responsabilidad internacional del Estado, son expresivas por sí mismas del carácter prevalente que se otorga al derecho internacional sobre los derechos nacionales (Rousseau, 1966, p. 17 y 19). En Colombia, cabe aclarar, tal carácter no es aceptado unánimemente por la doctrina (Molina, 2005, pp. 172 a 177) y la jurisprudencia (Sentencia C-400, 1998), pero lo cierto es que está evidentemente gravitando sobre todo un sistema de normas internacionales que tiene sus propias instancias de definición, que sí consideran la posibilidad de dicha prevalencia (Monroy, 2008, pp. 131-135).

Por otro lado, todo el sistema internacional de protección de los derechos humanos está atravesado por unos principios especiales como los de progresividad y pro homine. Este último es el que tiene clara incidencia en el sistema de fuentes, pues alude a un criterio hermenéutico en virtud del cual el operador jurídico debe apelar a la norma más amplia y favorable, o a la interpretación más extensiva y favorable, cuando se trate de reconocer derechos humanos y, del mismo modo, debe apelar a la norma o a la interpretación más restringida cuando de lo que se trata es de restringir tales derechos (Pinto, 1997, p. 163). 
La formulación de tal principio tiene una base positiva sólida en las normas internacionales (Vergara, 2015, p. 467), y permite hablar de por lo menos tres reglas específicas: a) la aplicación de la norma más protectora, b) la conservación de la norma más favorable y c) la interpretación con sentido tutelar (Henderson, 2004, pp. 93 y ss.). Estas reglas guardan enorme coincidencia con el principio de favorabilidad laboral estipulado en el artículo 53 de la Constitución colombiana, y son de gran utilidad en escenarios de conflictos normativos y desde los procesos de operación del derecho que se dan en el escenario judicial y administrativo.

\section{La necesaria relectura del sistema de fuentes del derecho de la función pública}

El contexto jurídico en el que se insertan las normas laborales propicia un modo distinto de ver el sistema de fuentes del derecho, al menos, en los escenarios en los que esta clase de normas resultan pertinentes, es decir, en todos aquellos en los que se configuran las relaciones de trabajo. En el ámbito público, estas relaciones tienen una configuración compleja, pues, de un lado, son tratadas como un medio a disposición del Estado para cumplir sus cometidos, necesitado, por tanto, de regulación por el derecho público; del otro, son expresión del trabajo humano y exigen el involucramiento del principio de protección especial al trabajo que se consagra en los niveles nacional e internacional.

Ahora bien, una lectura diferente de tal sistema exige poner de presente el dogma que ha imperado en el derecho colombia- no a ese respecto que, puede afirmarse, está ampliamente influenciado por el positivismo normativista kelseniano. De acuerdo con Kelsen (2009, pp. 118 y ss.), el ordenamiento jurídico constituye una estructura jerárquica cuyas normas se distribuyen en diversos estratos superpuestos, en cuya cúspide se encuentra la Constitución, luego las leyes y posteriormente los reglamentos (actos administrativos), estos dos últimos que pueden involucrar a su vez varios grados. Esta forma de ver el orden jurídico ha tenido especial relevancia dentro del derecho administrativo, como lo han hecho notar, entre otras, las obras de Merkl (Teoría general del derecho administrativo, 2004, pp. 127 y ss.), y García y Fernández (Curso de derecho administrativo, 1993, pp. 61 y ss.), y de modo particular para el derecho administrativo colombiano (Santofimio, 2004, pp. 337 y ss.), (Rodríguez, 2011, pp. 293 a 296) y (Vidal, 2004, pp. 15 y ss.), el cual cuenta, además, con la venia constitucional (artículos $4 .^{\circ}$ y 230 ) y jurisprudencial (Sentencia C-037, 2000).

La idea no es discutir la estructura citada, la cual contribuye indudablemente a entender la importancia jurídica de las distintas normas y sus respectivas relaciones de jerarquía; más bien apunta a llenar y ampliar su contenido y mostrar las interacciones que se generan entre las distintas fuentes en el preciso ámbito de la función pública, punto en el cual ganan importancia los criterios hermenéuticos que respaldan la norma laboral.

De modo general, los grados en que se ordenan las fuentes del derecho se man- 
tienen en su estructura básica piramidal: Constitución, ley y normas administrativas, estas últimas que revelan, a su vez, una jerarquía interna:

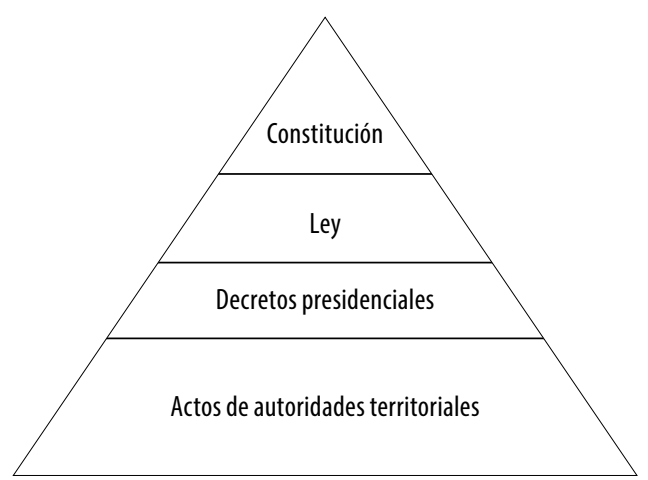

ESQUEMA TRADICIONAL DEL SISTEMA DE FUENTES
Ya, de modo particular, las variantes consideradas complementan tal estructura con fundamento en los conocidos conceptos de bloque de constitucionalidad, control de constitucionalidad, control de convencionalidad, control de legalidad y competencia, todos ellos matizados por el principio pro homine ya comentado y con un aplanamiento parcial de su original verticalidad.

El involucramiento de tales elementos suministra una visión ampliada del sistema de fuentes del derecho en el campo de la función pública, con la siguiente estructura5:

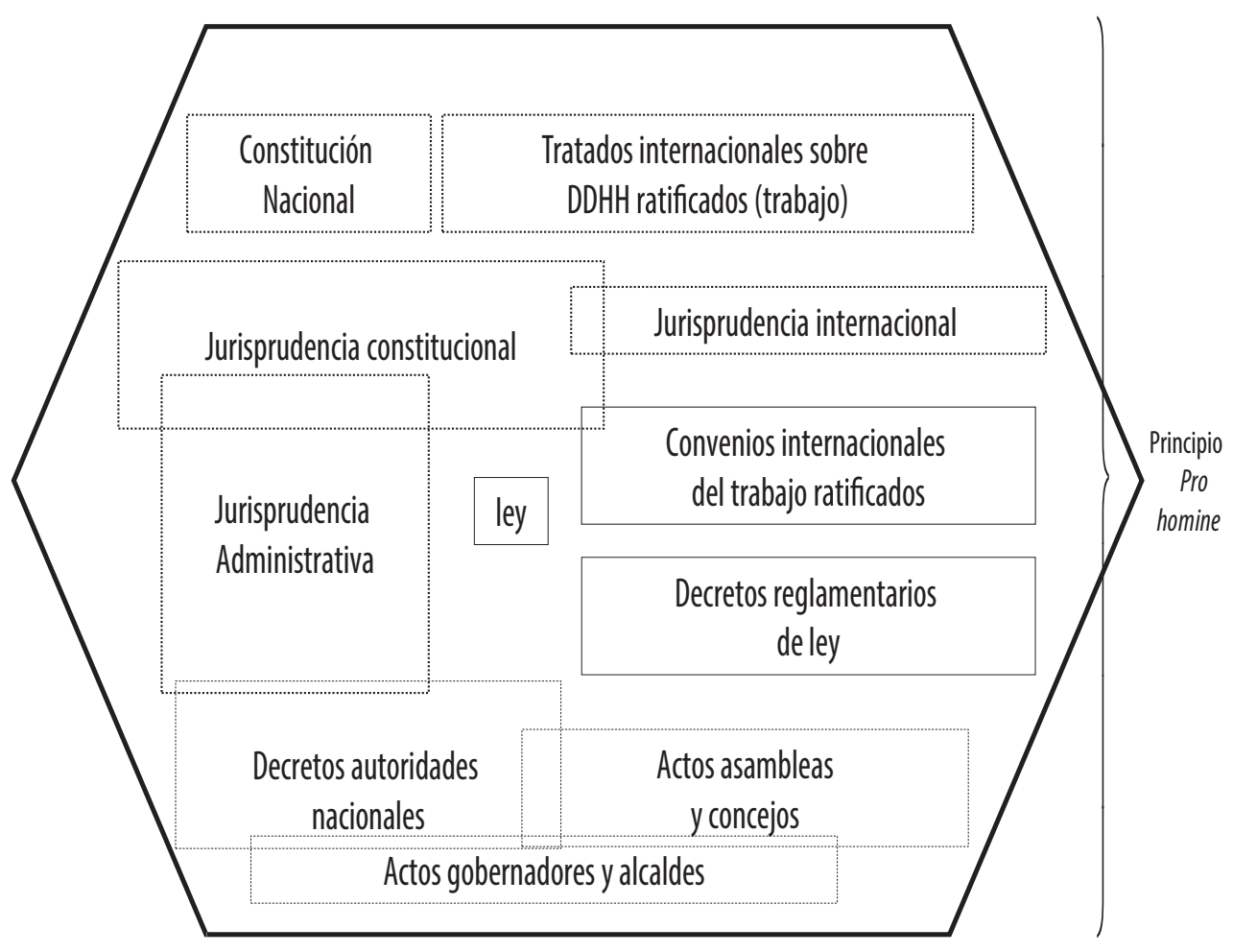

RELECTURA DEL SISTEMA DE FUENTES: SECTOR DE LA FUNCIÓN PÚBLICA

Fuente: elaboración propia. 
El esquema muestra cómo en el ámbito de la función pública el sistema de fuentes mantiene las jerarquías básicas (Constitución, ley actos administrativos), pero la posición de cada una de estas es compartida con otras fuentes que se involucran por factores distintos al origen de los actos. Del mismo modo, el esquema pone de presente que las fuentes están lejanas de ser herméticas, en razón de que en muchos campos pueden interactuar entre sí dinámicamente, en algunos por el factor jurisprudencial, en otros, por el factor competencial y colaborativo que se desprende de la Constitución.

\section{Cabe precisar mejor estos puntos:}

En primer lugar, en el renglón superior la jerarquía propuesta se integra por la Constitución y por los tratados internacionales sobre derechos humanos ratificados por Colombia, según lo prevé el artículo 93 de la Constitución colombiana. En este caso, como lo manifiesta Monroy (2008, pp. 132-133), se apela al concepto de bloque de constitucionalidad que, según la Corte Constitucional, adopta dos modalidades: una en estricto sensu, formada por todas aquellos tratados internacionales que consagran derechos humanos cuya limitación se encuentra prohibida durante los estados de excepción; la otra es la modalidad lato sensu, que involucra aquellos instrumentos internacionales, no importa su rango, que sirven como parámetro para realizar el control de constitucionalidad de la legislación interna, pues por virtud de ellos se interpreta el sentido y alcance de los derechos consagrados en la Carta Política. En esta última modalidad cobra particular importancia el sistema especializado de normas internacionales del trabajo de la OIT, en la medida en que muchos de sus convenios y recomendaciones dirigen la atención al desarrollo de derechos laborales que la Constitución colombiana consagró en diversas disposiciones, algunos de especial relevancia para el ámbito estatal.

El leve desvío que se observa a favor de los tratados internacionales obedece a la operatividad de los principios de pacta sunt servanda y buena fe que, se considera, son elementos válidos para proponer una solución a la hora de resolver conflictos normativos entre las normas nacionales e internacionales. Si bien este punto no ha logrado total claridad en el derecho colombiano, el artículo 9. de la Constitución declara el respeto y reconocimiento de los principios del derecho internacional aceptados por Colombia, cuyo componente de responsabilidad permite pensar en una prioridad, al menos provisional, de las normas allí consagradas sobre las del derecho interno, incluida la misma Constitución. Luego, el principio de pro homine proporcionará otras razones para esta solución.

En un segundo renglón, se incorporan la jurisprudencia constitucional y la jurisprudencia internacional sobre derechos humanos. En infinidad de oportunidades la Corte Constitucional ha defendido la fuerza vinculante de su jurisprudencia. Ha dicho al respecto que de la estructura piramidal, jerárquica o estratificada de las normas dentro del ordenamiento jurídico, se deriva la consideración del 
precedente judicial como fuente de derecho para todas las autoridades públicas (Sentencia T-954, 2013), más tratándose de la jurisprudencia constitucional que es la que tiene a su cargo las interpretaciones vinculantes de los preceptos de la Carta Política (Sentencia C-621, 2015). Ha llegado incluso a afirmar dicha Corporación que

Si en el sistema de fuentes las sentencias de la Corte Constitucional -por ser manifestaciones autorizadas y necesarias de la voluntad inequívoca de la Constitución-, prevalecen sobre las leyes, ellas igualmente resultan vinculantes para las distintas autoridades judiciales, que no pueden a su arbitrio sustraerse a la fuerza normativa de la Constitución, la cual se impone y decanta justamente en virtud de la actividad interpretativa de su guardián, tal y como se refleja en sus fallos (SU-640, 1998).

Como se indicó, a la par con la jurisprudencia constitucional, pero con una pequeña desviación a favor, se incorpora la jurisprudencia emanada de las cortes internacionales de justicia -la Corte Interamericana de Derechos Humanos es una de ellas-, mediante la cual interpretan y aplican las normas convencionales sobre derechos humanos a los que antes se aludió, y en las que radica la competencia de establecer el sentido y alcance de las disposiciones contenidas en esos instrumentos.

Por su parte, el control de convencionalidad, que ya es una realidad en el siste- ma interamericano $(C-792,2014)$, permite entender la interacción recíproca y permanente que se presenta entre la jurisprudencia nacional y la internacional, y entre los documentos constitucionales y los internacionales sobre los que ellas operan ${ }^{6}$.

El tercer renglón del sistema de fuentes congrega las normas con fuerza de ley, entre las cuales pueden existir grados, dependiendo del carácter orgánico, estatutario u ordinario de la ley. Sin embargo, aquí se trata esta fuente como una categoría única que, si bien en su momento fue considerada el principal origen del derecho, hoy se la debe estimar con un rango inferior, en la medida en que se ha tornado un objeto más de control constitucional, a partir de múltiples referentes jurídicos, entre los que se destacan los internacionales y jurisprudenciales, cuando son pertinentes. En este mismo renglón se ubican los convenios internacionales del trabajo ratificados por Colombia, en virtud de lo previsto en el artículo 53 de la Constitución, entre los que cabe destacar los adoptados en el seno de la OIT.

Tales convenios internacionales son ratificados por Colombia mediante un complejo procedimiento que involucra una aprobación por el Congreso y el control de constitucionalidad por parte

6 En muchos campos, incluso distintos a los laborales, la Corte Constitucional ha asumido un control de constitucionalidad de las leyes colombianas con base en las normas internacionales sobre derechos humanos, así como en la jurisprudencia y doctrina emanada de los organismos encargados de su interpretación y control. Para el efecto, cfr. (C-274, 2013) (C-438, 2013) (SU-555, 2014). 
de la Corte Constitucional. Es de suponer, entonces, que el rango jurídico que obtienen estos instrumentos es el mismo de la ley. No obstante, la diferencia radica en su carácter de tratados internacionales (Molina, 2005, pág. 90) que, como ya se ha destacado, se arropan bajo los principios de pacta sunt servanda y buena fe, que los ponen en una situación de privilegio respecto a las normas nacionales.

En un cuarto renglón se destacan las fuentes normativas de naturaleza administrativa, las cuales mantienen una alta dependencia de las normas legales que les sirven de fundamento. Ese es el caso de los actos expedidos en virtud de potestad reglamentaria que, habitualmente, están destinados a darle cumplimiento a la ley. Los reglamentos pueden revestir distintas modalidades; las más importantes son los reglamentos de ley ordinaria y los reglamentos de ley marco.

Los reglamentos de ley ordinaria tienen su fundamento en el artículo 189.11 de la Constitución, y su función es concretar los términos de la norma legal para darle efectiva aplicación, razón por la cual están imposibilitados para ampliar o reducir su contenido (Rodríguez, 2011, p. 384). Los de ley marco se fundamentan especialmente en el artículo 150.19 de la Constitución, disposición que los enmarca en términos mucho más flexibles que aquellos, precisamente por incidir sobre materias muy específicas y complejas que exigen mayor participación normativa por parte del ejecutivo, como ocurre, entre otras, con los salarios y las prestaciones sociales en el sector público. Se trata en este caso de una verdadera técnica colaborativa entre los órganos legislativo y ejecutivo, que responde una distribución competencial efectuada directamente por la Constitución, en virtud de la cual el primero establece los principios, normas generales, objetivos y criterios que guían la labor del segundo a la hora de regular con mayor precisión ciertos temas (Consejo de Estado, sentencia, 2008).

Si se observa bien, en los campos en los que opera la técnica de la norma marco se incorpora en la discusión el elemento competencial. Este elemento alude básicamente al ámbito de validez material que sujeta la actuación de las autoridades públicas creadoras de derecho (Robledo, 2010, p. 325). Como tal, alude al conjunto de asuntos que pueden ser atendidos por una autoridad pública de acuerdo con la distribución efectuada por la Constitución y la ley. La Corte Constitucional ha sostenido que en el caso de la ley marco los campos de competencia entre el legislador y el ejecutivo no se confunden, y eso indica que respecto de los temas que admiten esa técnica ninguno puede pretender hacerlo todo, es decir, no es dable a ninguno de ellos apropiarse de la esfera asignada al otro, pues eso acarrea inconstitucionalidad e invalidez de los actos por extralimitación de funciones (Sentencia C-955, 2000).

Lo anterior sugiere que el elemento competencial constituye un criterio determinante dentro del sistema de fuentes del derecho, que no solo atenúa la fuerza del criterio jerárquico sobre el que ha girado tradicionalmente su estructura y funcio- 
nalidad, sino que también introduce una dinámica de interacción efectiva entre las distintas fuentes del derecho, que opera con independencia del estatus que tenga el órgano que las produce. En el campo laboral estatal, este aserto tiene múltiples aplicaciones, sobre todo tratándose de asuntos que requieren manejos diferenciados, bien por el nivel administrativo en el que operan, ora por la necesidad lógica de otorgar competencias regulativas a distintas autoridades.

Dos ejemplos son representativos de esa interacción. El primero tiene que ver con el establecimiento de las plantas de empleo en las diferentes entidades públicas, en particular las del orden territorial. En este caso, la ley (Ley 909, 2004) establece los principios de la función pública colombiana, dispone las reglas generales relativas al empleo público y los criterios para su clasificación. El Presidente de la República, posteriormente, mediante una norma con fuerza de ley -por virtud de facultades extraordinarias- establece el sistema general de nomenclatura, clasificación y funciones de los empleos para las entidades del orden territorial (Decreto ley 785, 2005), que a la postre es la base para que estas entidades adopten sus propias plantas de personal, creando los empleos correspondientes y clasificándolos de acuerdo con su naturaleza, funciones y requisitos (Villegas, 2013, pp. 445 y ss.). La adopción de estas plantas es una competencia exclusiva de las autoridades territoriales y no de actos provenientes de autoridades nacionales como el Congreso o el Presidente de la República.
El otro ejemplo proviene del sistema salarial de los empleados públicos. En esa materia, y poniendo solo la atención en los incrementos anuales del salario, el Presidente de la República tiene la competencia para desarrollar la ley marco vigente sobre ese punto (Ley 4, 1992), respetando sus objetivos y criterios generales, entre los cuales se encuentra la prohibición de desmejora de los salarios y prestaciones de los servidores públicos (art. 2.a). Cada vigencia fiscal, el Presidente expide una serie de decretos con este propósito, estableciendo directamente el incremento para los servidores públicos del nivel nacional y el de los demás servidores no territoriales.

Para los empleados territoriales, la ley marco prevé que el presidente tiene la competencia para establecer el límite máximo salarial guardando equivalencias con cargos similares en el orden nacional (art. 12, parágrafo), lo cual implica que son las autoridades territoriales las que tienen la atribución de fijar el incremento respetando los topes dispuestos por el decreto nacional. En este punto, como lo ha resaltado la jurisprudencia de la Corte Constitucional, que es compartida en términos generales por el Consejo de Estado (Sección Segunda, 2015), la Constitución procura armonizar el principio de Estado unitario y el grado de autonomía que se reconoce a las entidades locales, de tal manera que al Congreso y al Gobierno les compete fijar los criterios y objetivos generales a los que se sujetan las entidades territoriales para el ejercicio de sus competencias, determinando los aspectos concretos del régimen salarial 
de sus servidores, previa consulta de sus particularidades presupuestales e institucionales (Sentencia C-402, 2013).

Así, entonces, en la definición de un asunto como el descrito, se observa una importante interacción entre distintas fuentes del derecho, en la que el factor competencial resulta clave. De ahí que, en ese específico tema, el comportamiento del sistema de fuentes se pueda diagramar de la siguiente manera:
Ahora bien, la jurisprudencia administrativa, que para estos efectos es la que se produce en el Consejo de Estado, la más alta instancia de la jurisdicción contencioso-administrativa, y que por efectos de esa posición tiene a su cargo la unificación jurisprudencial en ese ramo, es una fuente que interrelaciona todas las demás fuentes del derecho a la hora de interpretarlas y aplicarlas a los casos concretos, generando precedentes vinculantes para

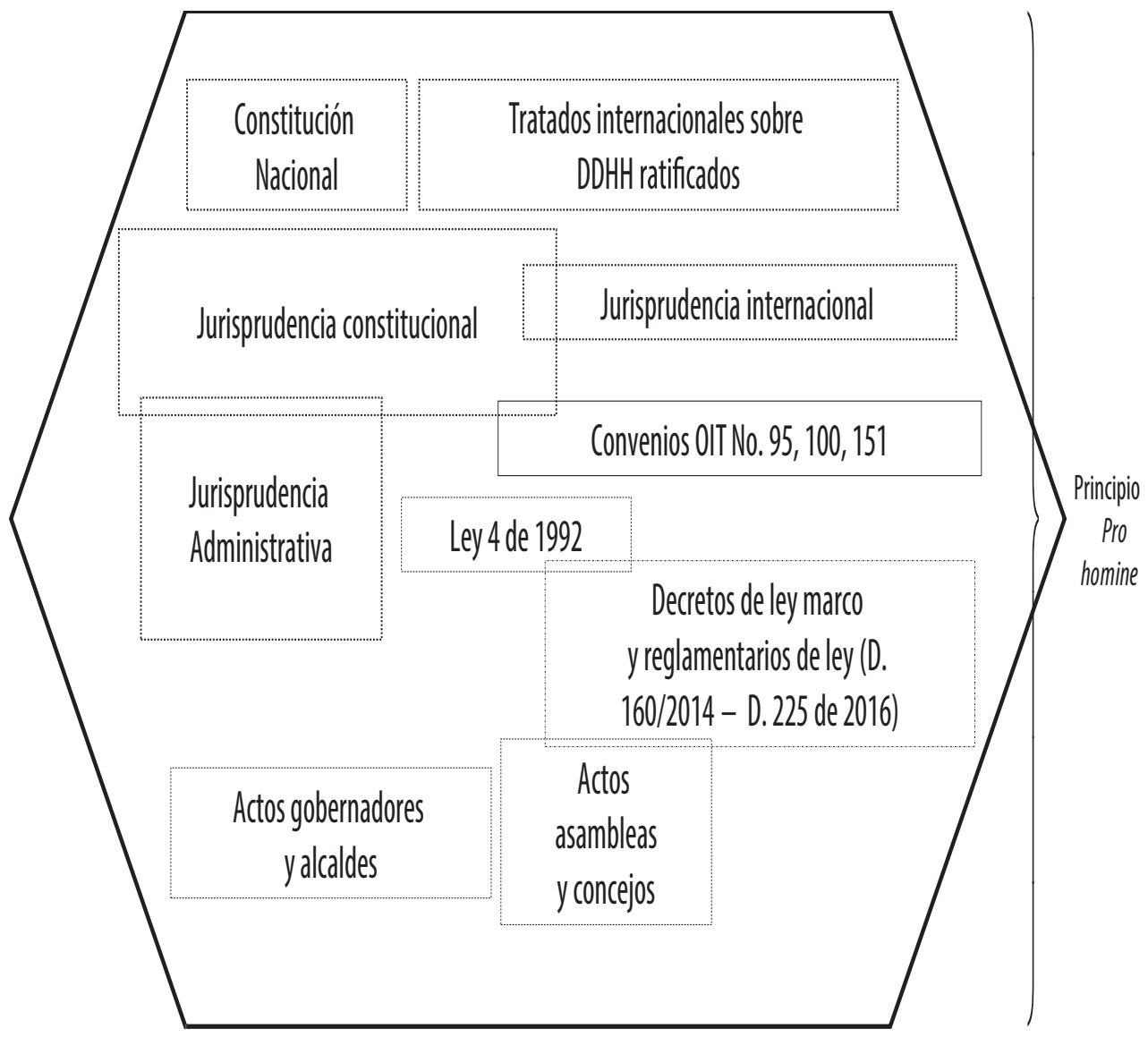

RELECTURA DEL SISTEMA DE FUENTES: RÉGIMEN SALARIAL

Fuente: elaboración propia. 
las demás autoridades públicas, en los términos definidos por la Corte Constitucional en la sentencia C-836 de $2001^{8}$. En particular, ese carácter es mucho más acentuado para las autoridades administrativas, que son las que operan cotidianamente todo el sistema jurídico en el curso de las relaciones laborales que tienen configuradas con sus empleados (Sentencia C-634, 2011).

Finalmente, el elemento decisivo de la proposición de relectura del sistema de fuentes del derecho, al menos cuando se trata de materias vinculadas con el trabajo humano, es el principio pro homine. En el esquema propuesto tal principio se introduce como un factor articulador de todas las fuentes y con pretensiones de operar en cualquiera de las escalas en que estas se hallen. Para eso, solo una de las variables que ofrece este principio es la que interesa destacar, y es la que guarda relación con el principio de favorabilidad laboral.

Henderson sostiene que tal variable implica:

[...] emplear la regla de interpretación pro homine, cuando a una determinada situación concreta, le es posible aplicar dos o más normas vigentes, nacionales e internacionales, cualquiera que sea su jerarquía. Con esta regla,

8 Cabe recordar, que el Consejo de Estado tiene la atribución de oficiar como juez constitucional en la modalidad de control abstracto, con lo cual complementa el sistema de vigilancia de la supremacía e integridad de la Carta Política confiado a la Corte Constitucional. Cfr. (Sentencia C-400, 2013). el juez y el intérprete deben seleccionar de entre varias normas concurrentes, y elegir aquella que contenga protecciones mejores o más favorables para el individuo o la víctima en relación con sus derechos humanos (2004, p. 93).

Se trata de una pauta dirigida a los operadores jurídicos en virtud de la cual deben, primero, indagar por las fuentes del derecho que resultan pertinentes para regular la relación laboral objeto de discusión y, posteriormente, escoger la que ofrezca mayor protección a los derechos laborales de los empleados, con independencia de su rango o posición dentro de sistema de fuentes.

Diferentes normas estructurantes del sistema de fuentes, tanto del orden interna cional como del constitucional, refuerzan el citado alcance del principio pro homine, tanto en el contexto universal (ONU, 1966, art. 5-2), como en el interamericano (OEA, 1988, art. 4), lo que coincide con el sistema de normas internacionales del trabajo, el primero que en el tiempo se refiere directamente al tema (OIT, 1919, art. 19-8). Cabe indicar que su respaldo en la Constitución colombiana se encuentra en el artículo 53, cuando consagra como principio mínimo de las relaciones de trabajo, la situación más favorable al trabajador en caso de duda en la aplicación de las fuentes formales de derecho.

De este modo, el sistema de fuentes en el derecho de la función pública no opera a la manera de la imperatividad de una fuente sobre otra por razón de su jerarquía o especialidad, e incluso, por razón de la 
competencia asignada a ciertas autoridades para regular el tema, sino a partir de un juicio de favorabilidad que, en caso de concurrencia de fuentes, conduzca a escoger aquella que resulte más favorable a la situación jurídica del empleado.

Si se acoge esta consecuencia, muchos de los asuntos problemáticos que ha generado el régimen salarial de los servidores públicos en los últimos años, sobre todo cuando se debate la competencia que tienen las autoridades territoriales para crear conceptos salariales, podrían tener una solución distinta a la simple declaratoria de nulidad por parte de la jurisdicción contencioso-administrativa. Ello, por razón de que el involucramiento de la norma laboral impediría, en un buen número de casos, que en esta clase de asuntos solo se debatan los problemas de derecho público.

\section{CONCLUSIONES}

La relación de trabajo que sostienen los empleados públicos con el Estado, que es una relación laboral de corte estatu tario, tiene la vocación de ser regulada por un complejo sistema de fuentes del derecho, en el que convergen normas de derecho público y de derecho laboral. Estas normas pueden tener origen en distintas instancias estatales e, incluso, internacionales, lo que produce una convergencia normativa que puede conllevar conflictos normativos y, de ese modo, generar la necesidad de utilizar herramientas apropiadas para resolverlos, tales como los tradicionales criterios de jerarquía y competencia.
El sector de la función pública, cuyo objeto es la gestión de este tipo de relaciones, no es asimilable a los demás en los que participa el Estado, pues involucra un conjunto de referentes jurídicos sui géneris que tiene su eje central en el principio de protección especial al trabajo, respaldado en normas constitucionales e internacionales sobre derechos humanos.

Factores como el de la jerarquía y la competencia siguen teniendo vigencia para estructurar el sistema de fuentes de la función pública colombiana, pero no de la manera acostumbrada, pues son acompañados por otras fuentes que se involucran por virtud y con la fuerza del derecho internacional y, en particular, por el que rige la protección de los derechos humanos. Los criterios que se desprenden de este orden, atravesado por los principios de pacta sunt servanda, buena fe, progresividad y pro homine, son suficientes para advertir cambios en ese sistema de fuentes, no solo porque logran aplanar la estructura piramidal que lo ha explicado, sino también porque sugieren la operación de sus diferentes escalas a partir de la articulación que produce el principio de favorabilidad, cuyo uso se concentra fundamentalmente en los escenarios de interpretación del derecho.

\section{REFERENCIAS BIBLIOGRÁFICAS}

Alexy, R. (2008). Teoría de los derechos fudamentales. Madrid: Centro de Estudios Políticos y Constitucionales.

Balbín, E. (2005). Unilateralismo y negociación colectiva en la administración pública. Lima: Fondo Editorial Universidad Católica del Perú. 
Beaudonnet, X. (2009). Derecho internacional del trabajo y derecho interno. Turín: Centro Internacional de Formación de la OIT.

Bobbio, N. (1981). El problema de la guerra y las vías de la paz. Barcelona: Gedisa.

Bresser Pereira, L. (1998). La reforma del Estado de los años noventa. Lógica y mecanismos de control. Desarrollo Económico, 38 (150), 517-550.

Canessa, M. (2006). Los derechos humanos laborales en el derecho internacional. Getafe: Universidad Carlos III de Madrid.

Consejo de Estado de Colombia (2008), Sentencia de la Sección Tercera del 14 de septiembre de 2008.

Consejo de Estado de Colombia (2015) Sentencia de la Sección Segunda del 6 de mayo de 2005.

Corte Interamericana de Derechop Humanos (2006), "Caso Almonacid Arellano y otros contra Chile" Sentencia del 26 de septiembre de 2006.

Corte Constitucional de Colombia (1992) Sentencia T-457 de 1992.

Corte Constitucional de Colombia (1998) Sentencia C-400 de 1998.

Corte Constitucional de Colombia (1998) Sentencia SU-640 de 1998.

Corte Constitucional de Colombia (2000) Sentencia C-037 de 2000.

Corte Constitucional de Colombia (2000) Sentencia C-955 de 2000.

Corte Constitucional de Colombia (2006) Sentencia T-097 de 2006.

Corte Constitucional de Colombia (2008). Sentencia SU-484 de 2008.

Corte Constitucional de Colombia (2009) Sentencia C-614 de 2009.
Corte Constitucional de Colombia (2011) Sentencia c-634 de 2011.

Corte Constitucional de Colombia (2012) Sentencia C-969 de 2012.

Corte Constitucional de Colombia (2013) Sentencia C-274 de 2013.

Corte Constitucional de Colombia (2013) Sentencia C-400 de 2013.

Corte Constitucional de Colombia (2013) Sentencia C-402 de 2013.

Corte Constitucional de Colombia (2013) Sentencia C-438 de 2013.

Corte Constitucional de Colombia (2013) Sentencia T-954 de 2013.

Corte Constitucional de Colombia (2013) Sentencia SU-712 de 2013.

Corte Constitucional de Colombia (2014) Sentencia SU-555 de 2014.

Corte Constitucional de Colombia (2014) Sentencia C-593 de 2014.

Corte Constitucional de Colombia (2014) Sentencia C-792 de 2014.

Corte Constitucional de Colombia (2015) Sentencia C-621 de 2015.

De la Cueva, M. (1990). El nuevo derecho mexicano del trabajo. México: Porrúa.

Del Hierro, L. (2000). ¿Qué derechos tenemos? Doxa, (23), 351-375.

Fernández, J. (1986). Empleo público y el derecho del trabajo. En Legislación del Trabajo, (408), 883-892.

Ferrajoli, L. (2010). Democracia y garantismo. Madrid: Trotta.

García de Enterría, E. (1963). La figura del contrato administrativo. Revista de Administración Pública, (41), 99-130. 
García, E. E. Fernández, T. (1993). Curso de derecho administrativo (Vol. I). Madrid: Civitas.

Gordillo, A. (2011). Tratado de derecho administrativo y obras selectas. (10 ed., Vol. 3). Buenos Aires: FDA.

Guastini, R. (1999). Distinguiendo. Estudios de teoría y metateoría del derecho. Barcelona: Gedisa.

Henderson, H. (2004). Los tratados internacionales de derechos humanos en el orden interno: la importancia del principio pro homine. Revista del IIDH, (39), 71-99.

Kelsen, H. (2009). Teoría pura del derecho. Buenos Aires: Eudeba.

Lopera, G. (2006). Principio de proporcionalidad y ley penal. Madrid: Centro de Estudios Políticos y Constitucionales.

Medina, D. L. (2004). La teoría impura del derecho. La transformación de la cultura jurídica latinoamericana. Bogotá: Uniandes-Unal-Legis.

Merkl, A. (2004). Teoría general del derecho administrativo. Granada: Comares.

Molina, C. (2005). Las normas internacionales del trabajo y su efectividad en el derecho colombiano. Bogotá: Temis.

Monroy, M. (2008). El derecho internacional como fuente del derecho constitucional. Anuario Colombiano de Derecho Internacional, (1), 107-138.

OEA. (1988). Protocolo adicional a la Convención Americana sobre Derechos Humanos "Protocolo de San Salvador". San Salvador: Asamblea General.

OIT. (1919). Constitución de la OIT. Washington: Sociedad de las Naciones.

OIT. (2006). Recomendación sobre la relación de trabajo núm. 198. Ginebra: Conferencia General.

ONU. (1966). Pacto internacional de derechos económicos, sociales y culturales. Nueva York: Asamblea General.
ONU. (1969). Convención de Viena. Austria: Conferencia de Plenipotenciarios.

Otto, I. D. (1988). Derecho constitucional-sistema de fuentes. Barcelona: Ariel.

Pinto, M. (1997). El principio pro homine. Criterios de hermenéutica y pautas para la regulación de los derechos humanos. En Abregú, M. E Courtis, C. La aplicación de los tratados sobre derechos humanos por los tribunales locales. Buenos Aires: Editorial del Puerto.

Presidencia de la República de Colombia. (1950). Decreto Ley 2663 de 1950. Bogotá: Presidencia de la República de Colombia.

Presidencia de la República de Colombia. (1968). Decreto Ley 3135 de 1968. Bogotá: Presidencia de la República de Colombia.

Presidencia de la República de Colombia. (1969). Decreto Reglamentario de 1848. Bogotá: Presidencia de la República de Colombia.

Presidencia de la República de Colombia. (1978). Decreto Extraordinario 1045 de 1978. Bogotá: Presidencia de la República de Colombia.

Presidencia de la República de Colombia. (2005). Decreto ley 785 de 2005. Bogotá: Presidencia de la República de Colombia.

República de Colombia. (1945). Ley 6 de 1945. por la cual se dictan algunas disposiciones sobre convenciones de trabajo, asociaciones profesionales, conflictos colectivos y jurisdicción especial de trabajo. Bogotá: República de Colombia.

República de Colombia. (1991). Constitución Política de Colombia de 1991. Bogotá: República de Colombia.

República de Colombia. (1992). Ley 4 de 1992. Mediante la cual se señalan las normas, objetivos y criterios que debe observar el Gobierno Nacional para la fijación del régimen salarial y prestacional de los empleados públicos, de los miembros del Congreso Nacional y de la Fuerza Pública y para la fijación 
de las prestaciones sociales de los Trabajadores Oficiales y se dictan otras disposiciones, de conformidad con lo establecido en el artículo 150, numeral 19, literales e) y f) de la Constitución Política. Bogotá: República de Colombia.

República de Colombia. (1998). Ley 489 de 1998. por la cual se dictan normas sobre la organización y funcionamiento de las entidades del orden nacional, se expiden las disposiciones, principios y reglas generales para el ejercicio de las atribuciones previstas en los numerales 15 y 16 del artículo 189 de la Constitución Política y se dictan otras disposiciones. Bogotá: República de Colombia.

República de Colombia. (2004). Ley 909 de 2004. por la cual se expiden normas que regulan el empleo público, la carrera administrativa, gerencia pública y se dictan otras disposiciones. Bogotá: República de Colombia.

República de Colombia. (2011). Ley 1437 de 2011. Por la cual se expide el Código de Procedimiento Administrativo y de lo Contencioso Administrativo. Bogotá: República de Colombia.

Rivero, J. (2002). Páginas de derecho administrativo. Bogotá: Temis-Universidad del Rosario.

Robledo, P. (2010). La autonomía municipal en Colombia. Bogotá : Universidad Externado de Colombia.

Rodríguez, L. (2011). Derecho administrativo (16 ed.). Bogotá: Temis.

Ross, A. (2007). Teoría de las fuentes del derecho. Madrid: Centro de Estudicos Políticos y Constitucionales .
Rousseau, C. (1966). Derecho internacional público. Barcelona: Ariel.

Sagües, N. (2012). Derecho internacional y derecho constitucional. Dificultades operativas del control de convencionalidad en el sistema interamericano. En H. Ahrens, El Estado de derecho hoy en América Latina (pp. 21-29). México D. F.: Fundación Konrad Adenauer.

Santofimio, J. (2004). Tratado de derecho administrativo (Vol. I). Bogotá: Universidad Extrenado de Colombia.

Válticos, N. (1977). Derecho internacional del trabajo. Madrid: Tecnos.

Vergara, H. D. (2012). Derecho del trabajo y jurisdicción contencioso administrativa. Una reflexión desde la idoneidad judicial. Estudios de Derecho, 69 (154), 131-159.

Vergara, H. D. (2015). ¿Rige el derecho del trabajo en la función pública colombiana? Un estudio desde la justicia administrativa. Opinión Jurídica, 14 (27), 175-192.

Vergara, H. D. (2015). La regla de favorabilidad y el principio pro homine en la función pública colombiana. A propósito del problema del nombramiento provisional. Revista de la Facultad de Derecho y Ciencias Políticas UPB, 45 (123), 453-480.

Vidal, J. (2004). Derecho administrativo. Bogotá: Legis.

Villegas, J. (2013). Derecho administrativo laboral. Bogotá: Legis. 